\title{
Friction Stir Welding of GR-Cop 84 for Combustion Chamber Liners
}

\author{
Carolyn K. Russell and Robert Carter ${ }^{\dagger}$ \\ NASA/Marshall Space Flight Center, Huntsville, Alabama 35812 \\ David L. Ellis ${ }^{\ddagger}$ \\ NASA/Glenn Research Center, Cleveland, Ohio 44111 \\ and \\ Richard Goudy $\$$ \\ Spin Tech, Paso Robles, California 93446
}

\begin{abstract}
GRCop-84 is a copper-chromium-niobium alloy developed by the Glenn Research Center for liquid rocket engine combustion chamber liners. GRCop-84 exhibits superior properties over conventional copper-base alloys in a liquid hydrogen-oxygen operating environment. The Next Generation Launch Technology program has funded a program to demonstrate scale-up production capabilities of GR-Cop 84 to levels suitable for main combustion chamber production for the prototype rocket engine. This paper describes a novel method of manufacturing the main combustion chamber liner. The process consists of several steps: extrude the GR-Cop 84 powder into billets, roll the billets into plates, bump form the plates into cylinder halves and friction stir weld the halves into a cylinder. The cylinder is then metal spun formed to near net liner dimensions followed by finish machining to the final configuration. This paper describes the friction stir weld process development including tooling and non-destructive inspection techniques, culminating in the successful production of a liner pre-form completed through spin forming.
\end{abstract}

\section{Nomenclature}

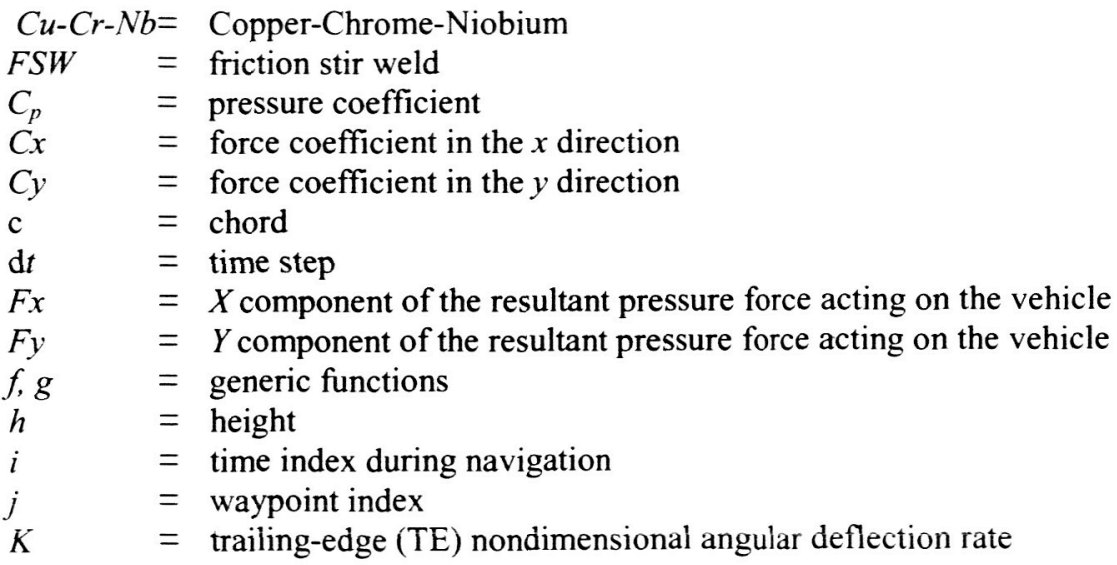

\footnotetext{
- Aerospace Welding Engineer, Materials, Processes \& Manufacturing, ED33.

${ }^{+}$Aerospace Welding Engineer, Materials, Processes \& Manufacturing, ED33.

‡ Insert Job Title, Department Name, Address/Mail Stop, and AIAA Member Grade for third author.

$\S$ President, 500 Linne Rd. Unit F.
} 


\section{Background}

\section{A. Alloy Design and Development}

The $\mathrm{Cu}$-Cr-Nb system was first examined for rocket engine applications under NASA's Earth-To-Orbit Program ${ }^{1,2}$. The goal was to develop a high thermal conductivity material with high tensile strength, long creep lives and long low cycle fatigue (LCF) lives. To reduce thermally induced stresses, a low coefficient of thermal expansion (CTE) was also desired.

Examination of the metallic elements showed that the four elements with the highest thermal conductivities were aluminum, gold, copper and silver in order of increasing thermal conductivity. Aluminum melts at too low a temperature to be useful while gold is too dense for a rocket engine application. Of the two remaining elements, silver has only a slightly higher thermal conductivity than copper but melts $123^{\circ} \mathrm{C}\left(221^{\circ} \mathrm{F}\right)$ lower than copper. Based upon these considerations, copper was chosen as the base element.

To achieve a combination of high strength and conductivity, either dispersion strengthening or precipitation strengthening works best ${ }^{3}$. Precipitation strengthening was chosen as the primary strengthening mechanism for the alloy for processing reasons. To further reduce the solubility of the secondary phase in the base element, a binary compound was desired. It was advantageous to have the compound's constituents have low solid solubility in copper but high solubility in liquid copper. Examination of the available binary and ternary phase diagrams revealed that $\mathrm{Cr}$ and $\mathrm{Nb}$ formed the high melting point intermetallic compound $\mathrm{Cr}_{2} \mathrm{Nb}$, had minimal solid solubility in solid copper, and were completely soluble in liquid copper.

Maximizing the volume fraction and minimizing the size of the $\mathrm{Cr}_{2} \mathrm{Nb}$ secondary phase would maximize the strength of the alloy ${ }^{4}$. Rapid solidification processing such as chill block melt spinning and gas atomization can be used to form extended solid solutions from which a secondary phase such as $\mathrm{Cr}_{2} \mathrm{Nb}$ can be precipitated ${ }^{5}$. The ribbon or powder produced can be consolidated by conventional powder metallurgy methods, and the consolidated material processed like other copper alloys.

In practice it became evident that the vast majority of the $\mathrm{Cr}_{2} \mathrm{Nb}$ precipitates in the liquid phase even with rapid solidification techniques. This led to dispersion strengthening instead of precipitation strengthening. This still gives the $\mathrm{Cu}-\mathrm{Cr}-\mathrm{Nb}$ alloys excellent strength while retaining a high thermal conductivity.

Based upon examination of alloys with $\mathrm{Cr}$ contents ranging from 2 to 10 atomic percent and $\mathrm{Nb}$ contents ranging from 1 to 5 atomic percent with a constant $\mathrm{Cr}: \mathrm{Nb}$ ratio of $2: 1^{6}$, the best combination of properties and processability appears to be obtained with 8 atomic percent $\mathrm{Cr}$ and 4 atomic percent $\mathrm{Nb}$. This alloy was designated GRCop-84 and selected for further analysis and scale-up.

\section{B. Comparison of GRCop-84 to Other Copper-Based Liner Materials}

There are five major properties used to determine the suitability of an alloy for use in a regeneratively cooled rocket engine liner - tensile strength, creep resistance, low cycle fatigue, thermal expansion and thermal conductivity. Of the five, thermal conductivity and low cycle fatigue or low cycle fatigue-creep are generally the most important for designing a liner.

There are several copper-based engine liners in use with several more proposed by various engine programs. The engine designs tend to use one of five alloys - pure copper, NARloy-Z (Cu-3 w/o Ag-0.5 w/o Zr), GlidCop AL-15 $\left(\mathrm{Cu}-0.7\right.$ v/o $\left.\mathrm{Al}_{2} \mathrm{O}_{3}\right)$ or AL-60 $\left(\mathrm{Cu}-2.7\right.$ v/o $\left.\mathrm{Al}_{2} \mathrm{O}_{3}\right)$, and AMZIRC or Zirconium Copper ( $\mathrm{Cu}-0.15 \mathrm{w} / \mathrm{o} \mathrm{Zr}$ ). The field is generally further reduced by the elimination of GlidCop AL-60 due its 10\% lower thermal conductivity relative to GlidCop AL-15 with little increase in other properties. In general, most comparisons are done to NARloy- $Z$ since it is the alloy currently in use for the Space Shuttle Main Engine liner.

GRCop- 84 has been consolidated by both extrusion and Hot Isostatic Pressing (HIPing). Both methods produced fully consolidated material. Samples from both consolidation techniques were given a simulated braze thermal cycle with a maximum temperature of $935^{\circ} \mathrm{C}$ $\left(1715^{\circ} \mathrm{F}\right)$ to examine the stability of the alloy.

Figure 1 shows the yield strength of the various alloys in a variety of conditions. For alloys that have data taken

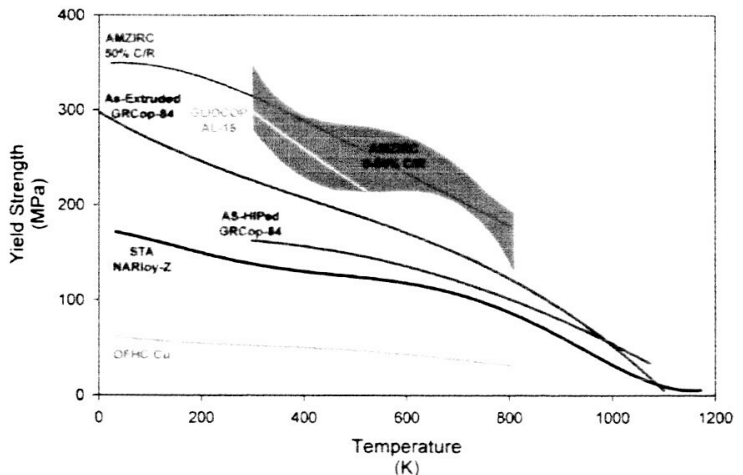

Figure 1: Yield strength of candidate liner alloys. References: $\mathrm{Cu}^{10}$, Solution Heat Treated and Aged (STA) NARloy-Z ${ }^{11}$, GlidCop AL-15 ${ }^{10}$, AMZIRC ${ }^{10,12}$ 
from muitiple sources, a range is shown that encompasses the values reported.

GRCop-84 given a HIP cycle is exposed to higher temperatures and undergoes more coarsening than the extruded GRCop-84. As a result, the yield strength is slightly lower. GRCop- 84 has higher yield strengths than NARloy-Z over the entire temperature range of interest. The GlidCop alloys have higher yield strengths near room temperature, but the advantage disappears at elevated temperatures such a $500^{\circ} \mathrm{C}\left(932^{\circ} \mathrm{F}\right)$, the anticipated hot wall temperature of the liner. AMZIRC, which derives almost all of its strength from cold work, has higher yield strengths than as-produced (no cold work) GRCop- 84 .

Little open literature is available on the effect of high temperature exposures such as one experienced in a brazing operation on these copper-based alloys. What data has been found for these alloys are shown in Fig. 2.

For copper, there should be little change in properties since the material is already fully annealed, but there will be considerable grain growth which may have limited deleterious effects. Increasing the grain size from $0.060 \mathrm{~mm}$ to $0.850 \mathrm{~mm}(0.002$-inch to 0.033 -inch $)$ decreases the room temperature yield strength $14 \mathrm{MPa}(2 \mathrm{ksi})$ ?

AMZIRC softens when exposed to temperatures between $350^{\circ} \mathrm{C}$ and $600^{\circ} \mathrm{C}\left(572^{\circ} \mathrm{F}\right.$ and $\left.1112^{\circ} \mathrm{F}\right)^{8}$. Following a 30 minute exposure above $600^{\circ} \mathrm{C}$, the room temperature yield strength of AMZIRC decreases to approximately $250 \mathrm{MPa}$ (36.2 ksi).

GlidCop AL-15 Low Oxygen Grade has been tested following a $980^{\circ} \mathrm{C}\left(1796^{\circ} \mathrm{F}\right)$ simulated braze cycle and a $100 \mathrm{~h}$ anneal at $1040^{\circ} \mathrm{C}\left(1904^{\circ} \mathrm{F}\right)$ by Stephens et al $^{9}$. The simulated braze cycle had little effect on the yield and ultimate tensile strengths but did increase ductility slightly. The long term, high temperature annealed material which resulted in considerable coarsening of the grains reduced the yield strength to around 125 MPa (18.1 ksi) but enhanced ductility from $17.5 \%$ to $23.5 \%$ total elongation.

The effect of the high temperature braze cycle on GRCop-84 depended upon the prior processing. The yield strength of extruded material which was processed well below the braze temperature and experienced shorter thermal exposures during processing decreased 21-35 $\mathrm{MPa}(3-5 \mathrm{ksi})$ across the temperature range tested. HIPed material which saw a long time at elevated temperatures during consolidation was virtually unaffected. The excellent retention of properties following extended high temperature exposures is one of the major benefits of GRCop- 84 .

Creep lives of the various materials come from a variety of sources and cover a wide range of temperatures and stresses. To compensate for these variations, the data was plotted on a Larson-Miller plot using an assumed value of $c=17$. While the limitations of the Larson-Miller analysis are recognized, the plot does allow for a semi quantitative comparison of the alloys' creep properties. The results are presented in Fig. 3.

Compared to the other alloys, GRCop-84 has excellent creep resistance. The creep life at a given stress can be increased by two or even three orders of magnitude over NARloy-Z. Alternatively, GRCop-84 can support 10$15 \%$ greater stresses for a given life than NARloy- $Z$ can.

Low cycle fatigue is generally considered the prime mechanical property for selecting a liner material. Figure 4 shows the low cycle fatigue lives of several of the alloys. GlidCop AL-15 has poor LCF lives despite good strength and reasonable ductility. NARloy- $Z$ is better, but the best alloys are GRCop- 84 and AMZIRC. The GRCop-84 LCF lives were virtually unaffected by temperature between room temperature and $600^{\circ} \mathrm{C}$ $\left(1112^{\circ} \mathrm{F}\right)$ and were not statistically significantly affected

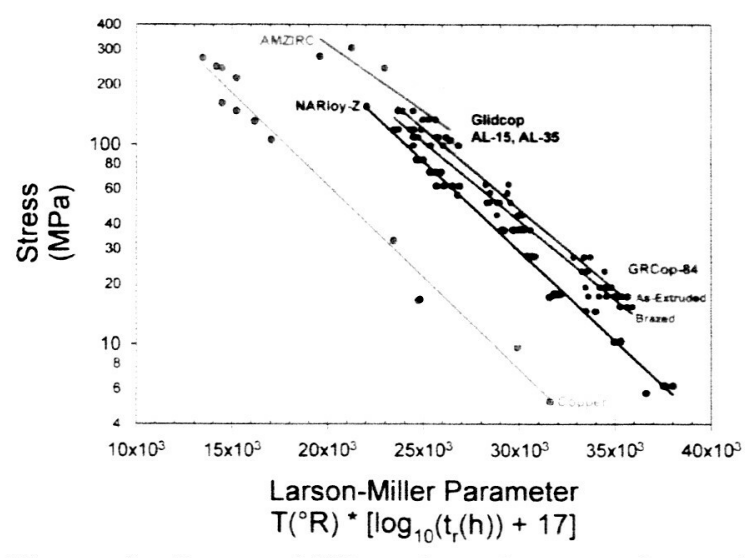

Figure 2: Larson-Miller plot of creep lives of candidate liner alloys. References: Copper $^{13}$, GlidCop AL-15, AL-35 ${ }^{13}$, AMZIRC $^{13}$, NARloy$\mathrm{Z}^{13}$ 
by the braze cycle. Only processing had a statistically significant effect, and that effect was fairly small.

Thermal expansion is important for a liner application since it causes thermally induced stresses that lead to creep and determines the total strain range for LCF. The thermal expansion of several of the alloys is shown in Fig. 5. Most of the candidate alloys fall within a very narrow band of thermal expansions that are approximately the same as pure copper. GRCop-84 with its 14 volume percent $\mathrm{Cr}_{2} \mathrm{Nb}$ has a much lower thermal expansion. Comparing averages, the thermal expansion of GRCop- 84 is about $15 \%$ lower than the other alloys at $500^{\circ} \mathrm{C}\left(932^{\circ} \mathrm{F}\right)$.

Figure 6 shows the thermal conductivity of the candidate liner alloys. Copper has the highest conductivity, and lightly alloyed AMZIRC is barely less than copper. The thermal conductivity of GlidCop is highly dependent on the volume fraction of alumina. AL-15 has an intermediate thermal conductivity while AL-60 tends to be at the low end. This large decrease in thermal conductivity is the main reason GlidCop AL-15 is normally preferred.

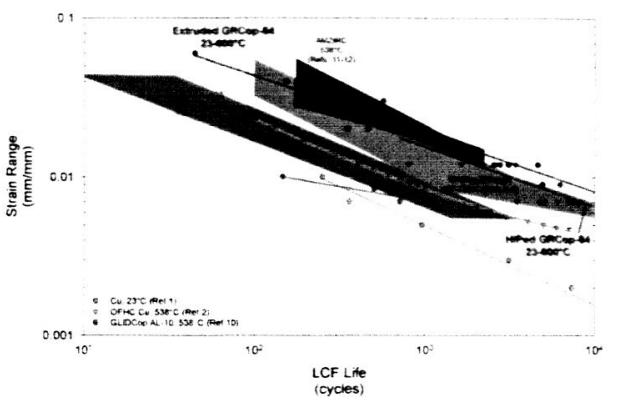

Figure 3: Low cycle fatigue lives of candidate liner alloys. References: Copper ${ }^{18,18}$, GlidCop AL-10 ${ }^{18}$, GlidCop AL-15 ${ }^{18}$, NARloy- $Z^{18}$

NARloy- $Z$ has an intermediate thermal conductivity that improves when the alloy is heated from room temperature to the anticipated hot wall temperature.

GRCop-84 has one of the lower thermal conductivities, but recent improvements in powder production to remove iron has increased the low temperature $\left(<350^{\circ} \mathrm{C}\right.$ or $\left.662^{\circ} \mathrm{F}\right)$ thermal conductivity. Compared to pure copper, GRCop- 84 retains more than $75 \%$ of the thermal conductivity of pure copper above room temperature.

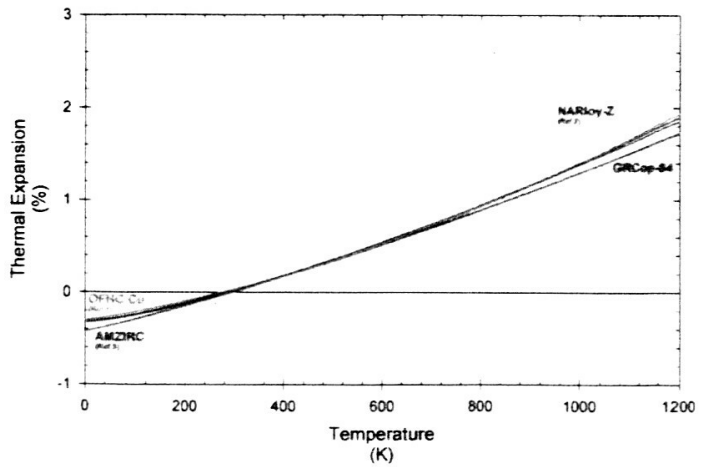

Figure 5: Thermal expansion of candidate liner alloys

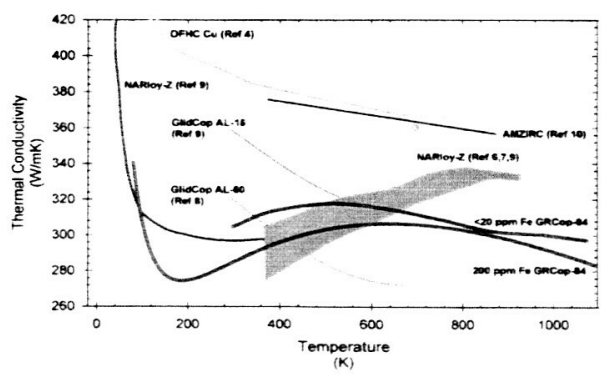

Figure 4: Thermal conductivity of candidate liner alloys

The lower thermal conductivity is a concern, but analysis of nonoptimized liner designs where GRCop- 84 is directly substituted for NARloy-Z with no reduction in wall thickness has shown that the hot wall temperature will only increase $6^{\circ} \mathrm{C}$ to $28^{\circ} \mathrm{C}\left(10^{\circ} \mathrm{F}\right.$ to $\left.50^{\circ} \mathrm{F}\right)$. GRCop- 84 can generally operate at temperatures up to $200^{\circ} \mathrm{C}\left(360^{\circ} \mathrm{F}\right)$ greater than NARloy-Z, so this increase is well within the temperature capabilities of the new alloy. If the wall can be thinned to take advantage of the superior mechanical properties of GRCop-84, the hot wall temperature can actually be decreased even with the lower thermal conductivity GRCop- 84 .

\section{Friction Stir Welding Process Background}

Friction Stir Welding (FSW) is a solid-state welding process that uses a non-consumable rotating pin-tool to make linear welds. Typical pin-tools consist of a cylindrical "shoulder" and a smaller diameter protruding "pin" (see Fig. 7). The process, shown schematically in Fig. 8, is initiated by plunging the rotating pin-tool into a weld joint until the shoulder is in intimate contact with the surface of the work piece (Fig. 8A). After the pin-tool has reached its final plunge depth a dwell-time is initiated wherein the material surrounding the pin-tool is heated by friction and plastic deformation (Fig. 8B). Travel is initiated after sufficient dwell-time, and the weld is created by literally stirring plasticized material together under compressive forces generated by the tool shoulder (Fig. 8C). Finally, the 
weld is concluded by halting travel and withdrawing the rotating pin-tool from the work piece (Fig 8D). It should be noted that a hole is left at the end of the weld when the pin-tool is withdrawn.

Friction Stir Welding is well suited for GRCop- 84 since no melting occurs. Because of this the $\mathrm{Cr}_{2} \mathrm{Nb}$ strengthening elements in GRCop-84 do not go into solution during welding. Also, heat affected zone width and grain growth due to localized heating are minimized. In fact there is significant grain refinement in the "stir zone" or "nugget" of the weld. Figure 9 shows a typical macrostructure of a Friction Stir Weld in GRCop-84.

To date the limited availability of GRCop- 84 plate material has hindered the development of a statistically significant friction stir welding mechanical properties database. However, roomtemperature tensile testing completed thus far is extremely

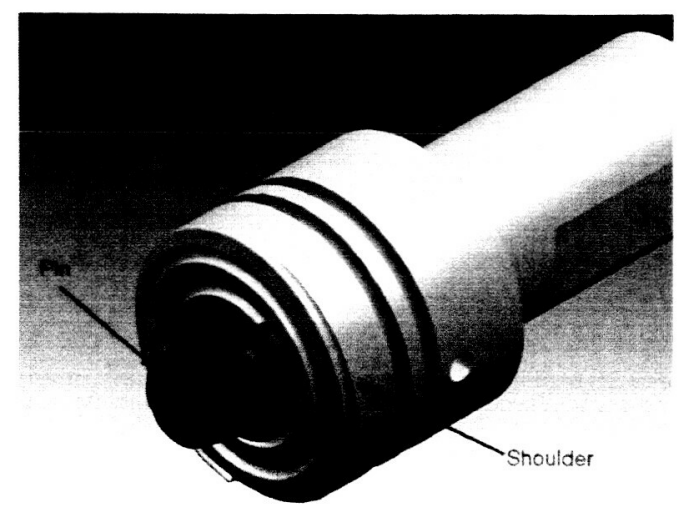

Figure 7: Friction Stir Welding Pin-Tool.

promising. Table 1 shows all tensile data collected to date. Note that this data was collected from friction stir welds in both $1.27 \mathrm{~cm}(0.5$ inch) thick, and $1.88 \mathrm{~cm}(0.75$ inch-thick rolled and annealed GRCop-84 plate material. Both "round bar" and "dog bone" type specimens were used. Of note is the fact that average yield strength is $88 \%$ of the extruded material strength, and average ultimate tensile strength is $95 \%$ of the extruded material strength. These are

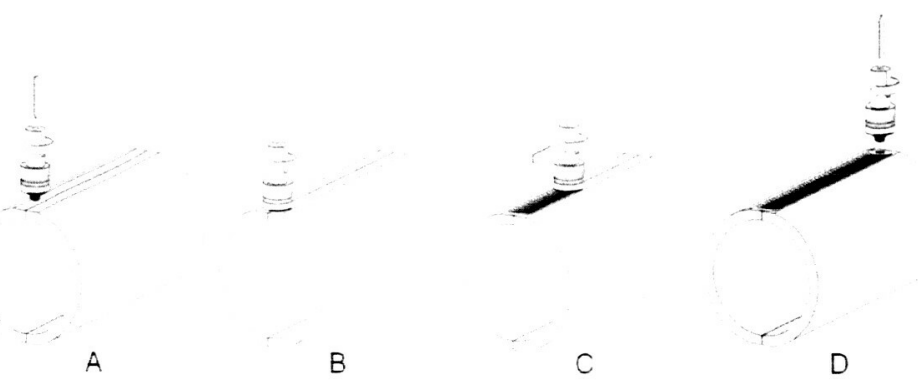

Figure 8: Friction Stir Welding Process. respectable numbers considering that welding parameters have not yet been optimized.

\section{Processing Welded Combustion Chamber Liners}

As mentioned previously, GRCop- 84 was designed for rapid solidification processing. On a commercial scale, the best option was conventional argon gas atomization. Scale-up work was done with Crucible Research of Pittsburgh, PA to produce up to $727 \mathrm{~kg}$ (1600 pounds) in a single atomization campaign. All powder was handled under argon or vacuum throughout production to minimize oxygen contamination. The powder was screened to ASTM -140 mesh $(<106 \mu \mathrm{m})$. The powder was placed in a $38.4 \mathrm{~cm}(15.1$-inch)

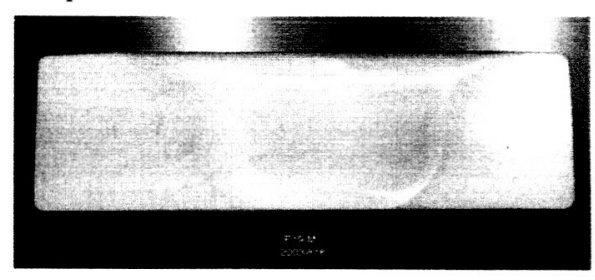

Figure 9: Typical short-transverse macrostructure of a friction stir weld in GRCop-84. diameter copper extrusion can. The can was evacuated while being heated and then sealed when a hard vacuum was obtained.

The extrusion was done at HC Starck in Coldwater, MI. The can was extruded to a $7.4 \mathrm{~cm} \mathrm{x} 25.1 \mathrm{~cm}(2.9$-inch $\mathrm{x}$ 9.9-inch) rectangular cross-section. The reduction in area was 6.2:1. Modeling by Deformation Control Technologies showed that nearly full consolidation was obtained prior to the breakthrough of the can during extrusion. The extruded product showed no visible porosity and considerable evidence of material flow.

For rolling, the extrusions were flattened, inspected, and cut to length. The upper and lower surfaces, corresponding to the two largest faces, were machined to remove all copper. This typically reduced the thickness to $6.4 \mathrm{~cm}$ (2.5-inches). The remaining copper can on the other faces was not removed since it would be trimmed from the plate after rolling.

Warm rolling of the extruded material to plate was done at $\mathrm{HC}$ Starck in Euclid, OH. A slightly elevated temperature was used to allow some recovery and even recrystallization and avoid failure of the material observed after cold reductions of approximately $30 \%$ in previous rolling work. The extrusions were rolled to a thickness of $1.27 \mathrm{~cm}(0.5$-inch $)$ and annealed to remove any residual stress and achieve a fully recrystallized microstructure. 
The plates were cut to the desired length.for the cylinders. The half cylinders were made by bump forming the plates, working from the center of the plate outwards shown in Fig. 10. Once the desired inner radius was obtained, the extra material was cut off and the ends machined to give a tight fit and uniform thickness. After forming the abutting weld lands were machined square and a flat was machined onto the outside diameter at each joint to assure good contact between the pin-tool shoulder and part depicted in Fig. 11.

Welding of the preforms took pace at the Marshall Space Flight Center (MSFC) using MSFC's Vertical Weld Tool. A special fixture was fabricated to accommodate welding of the cylinders. The fixture is water cooled to prevent excessive heat build up and/or distortion during welding, and

\begin{tabular}{|c|c|c|c|c|c|}
\hline & $\begin{array}{c}0.2 \% \text { Yield } \\
\text { (Ksi) }\end{array}$ & $\begin{array}{c}0.2 \% \text { Yield } \\
\text { (MPa) }\end{array}$ & UTS (Ksi) & UTS (MPa) & $\begin{array}{c}\text { Elongation } \\
(\%)\end{array}$ \\
\hline $1 \mathrm{P} 7-1$ & 29.7 & 204.8 & 58.3 & 402.1 & 19.0 \\
\hline $2 P 7-4$ & 29.0 & 199.9 & 58.4 & 402.9 & 20.7 \\
\hline 3 P10-1 & 29.2 & 201.3 & 58.5 & 403.6 & 18.3 \\
\hline $4 \mathrm{P} 10-4$ & 30.8 & 212.3 & 58.9 & 406.0 & 17.2 \\
\hline 5 P11-1 & 28.7 & 197.9 & 58.4 & 402.9 & 16.4 \\
\hline $6 P_{11-4}$ & 29.8 & 205.4 & 58.5 & 403.2 & 16.4 \\
\hline P12-RT2 & 30.3 & 208.9 & 59.9 & 413.1 & 15.4 \\
\hline P12-RT3 & 29.9 & 206.3 & 59.7 & 411.4 & 19.2 \\
\hline P12-RT4 & 30.6 & 210.9 & 59.5 & 410.3 & 18.8 \\
\hline P12-RT5 & 29.7 & 204.6 & 59.0 & 407.0 & 18.6 \\
\hline P12-RT6 & 28.9 & 199.1 & 59.1 & 407.2 & 16.3 \\
\hline P19-T3 & 29.4 & 202.9 & 58.0 & 399.7 & 18.8 \\
\hline P19-T4 & 28.6 & 197.1 & 57.5 & 396.7 & 18.6 \\
\hline P19-T5 & 28.8 & 198.5 & 56.8 & 391.6 & 16.3 \\
\hline Mean & 29.5 & 203.6 & 58.6 & 404.1 & 17.9 \\
\hline S.D. & 0.7 & 4.9 & 0.8 & 5.7 & 1.5 \\
\hline Extruded Material & 33.5 & 231.4 & 61.8 & 426.1 & 21.4 \\
\hline Joint Efficiency (\%) & \multicolumn{2}{|c|}{88.1} & \multicolumn{2}{|c|}{94.9} & 83.4 \\
\hline
\end{tabular}

Table 1 - Room-Temperature tensile data. also features a removable/replaceable anvil insert. Figure 12 shows a cylinder fixtured and ready to weld. Figure 13 shows the fixture and cylinders during welding.
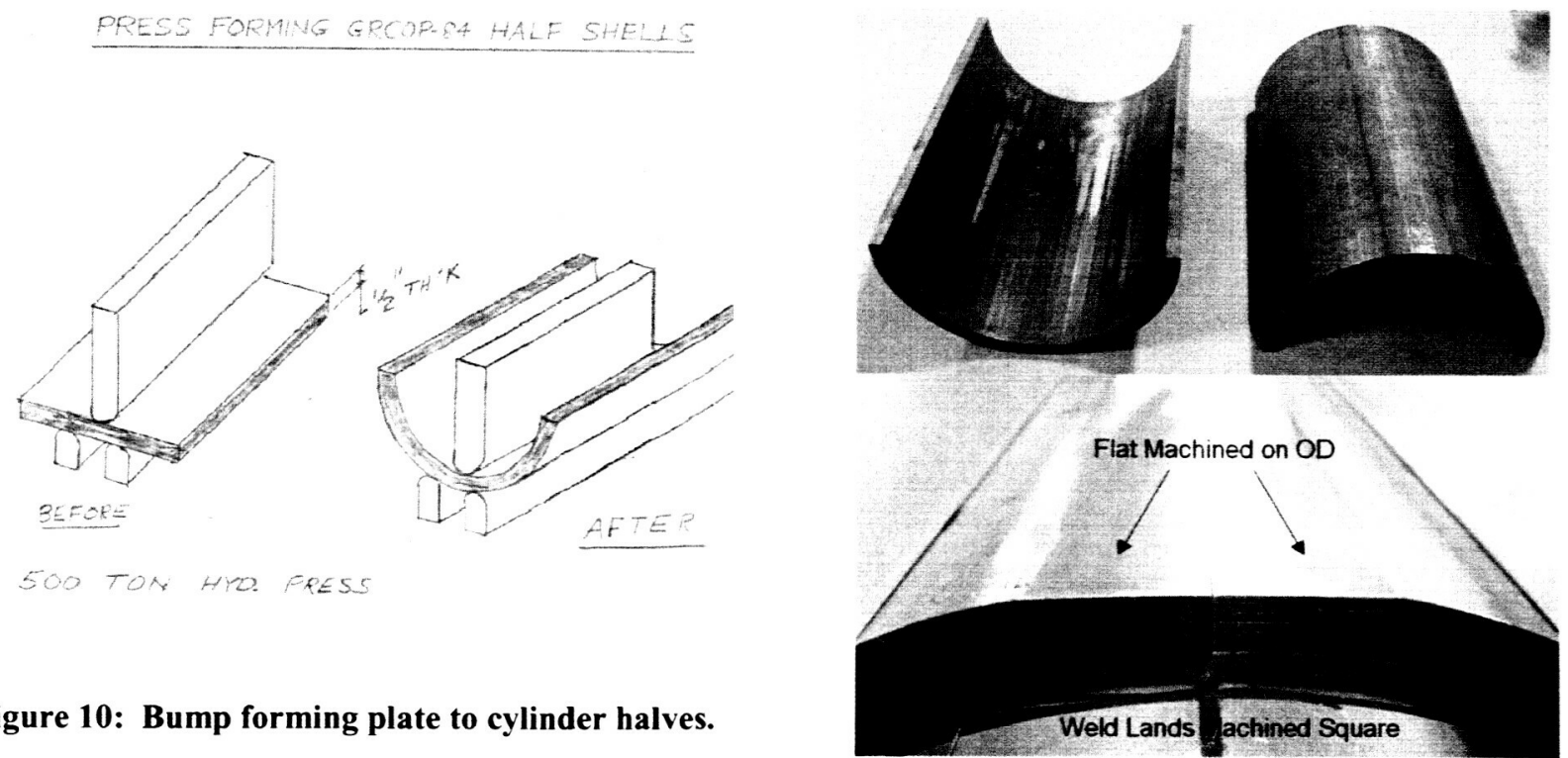

Figure 10: Bump forming plate to cylinder halves.

Figures 11: Bump formed and machined half cylinders prior to welding.

The pin tool used for welding GRCop-84 consisted of a Stellite alloy 6B body and MAR-M-246 alloy pin. Stellite $6 \mathrm{~B}$ was selected for the shoulder body due to its excellent wear resistance at elevated temperatures. MARM-246 was selected as the pin alloy due to its elevated temperature strength and toughness. MAR-M-246 also has good resistance to the rubbing-type wear the pin encounters during Friction Stir Welding.

The geometry of the shoulder (e.g. the scroll cut) was developed to allow welding without using a lead angle. This helps to reduce and eliminate the flashing, undercut, and weld-bead concavity common to conventional smooth-shouldered friction stir welding tools.

The pin was tapered along its length and included both threads and flutes to enhancing stirring of material. This geometry was developed to reduce traverse loads, thus increasing pin life and reducing wear. The diameter of the pin was selected such that no plastic deformation of the pin would occur under welding temperatures and loads. Any

6

American Institute of Aeronautics and Astronautics 


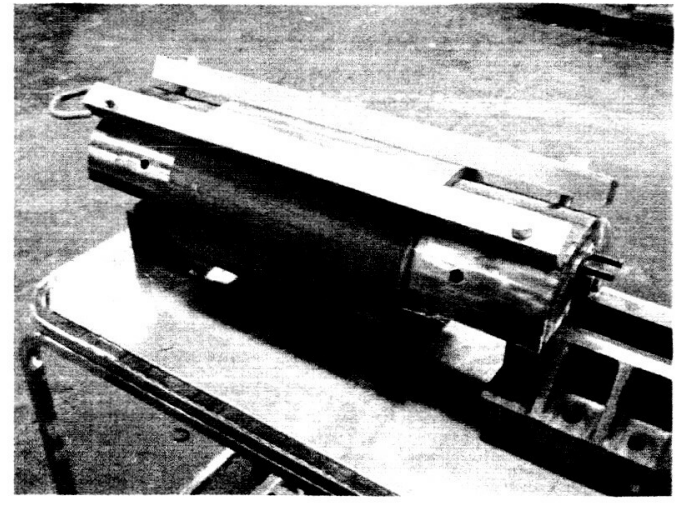

Figure 12: Cylinder welding fixture with clamps.

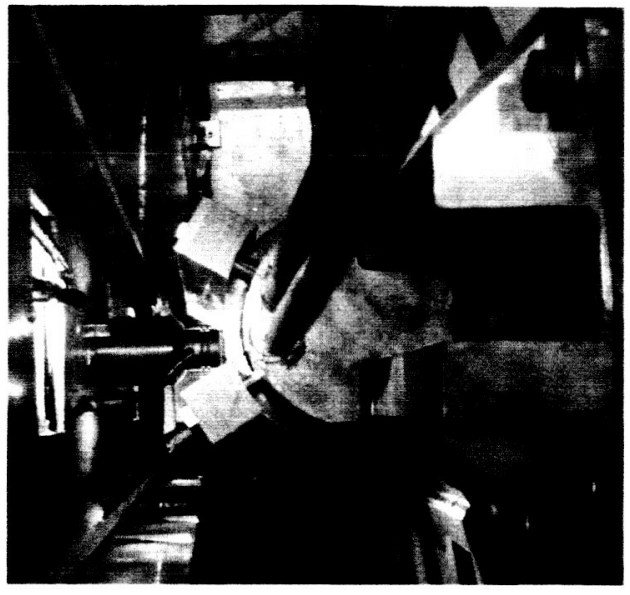

Figure 13: Fixture mounted during welding.

plastic deformation of the pin will lead to low cycle fatigue problems. The length of the pin was selected such that during welding there would be a $0.75 \mathrm{~mm}(0.030$ inch) gap (penetration ligament) between the tip of the pin and anvil. It was shown that with a $0.75 \mathrm{~mm}(0.030$ inch) gap this pin-tool is capable of achieving a full penetration weld.

After the preforms were fixtured and mounted in the Vertical Weld Tool, the entire volume containing the fixture and preform was purged with a mixture of argon and helium. This was done in order to prevent oxidation during welding. An oxygen analyzer was plumbed into the purge chamber and oxygen content was monitored before, during, and after welding. Welding did not commence until less than $1 \%$ oxygen was present in the purged volume. The purge was not broken until 10 minutes (minimum) after welding to allow the preform to cool below its oxidation temperature.

A partial-penetration tack weld was then made the entire length of the joint. This was done using a pin-tool with pin-length of approximately $2.5 \mathrm{~mm}(0.100 \mathrm{inch})$. Figure 14 shows the pin-tools used, the tack tool is on the right. The purpose of this tack weld was to reduce the clamping forces necessary during full-penetration welding. Significant transverse loads (perpendicular to the direction of travel) were observed during the full-penetration pass. Without tack welding it is very likely that the abutted joint would spread apart forming a gap. The pin and shoulder of the full-penetration tool were sized such that the entire tack weld region was consumed during the full-penetration pass.

After tacking, a hole was pre-drilled at the location where the full-penetration pin-tool would plunge into the cylinder. The hole was approximately half the nominal diameter of the pin and half the material thickness in depth. The primary purpose of this hole was to act as a pilot for the pin, relieving some of the plunge loads and also preventing the tool from walking around on the cylinder. In addition, the hole reduced the amount of material displaced by the pin during the plunging process, thus reducing the amount of heating that takes place during plunge. Before implementing the use of a pre-drilled hole for welding GRCop-84 there was a significant problem associated with excessive heat

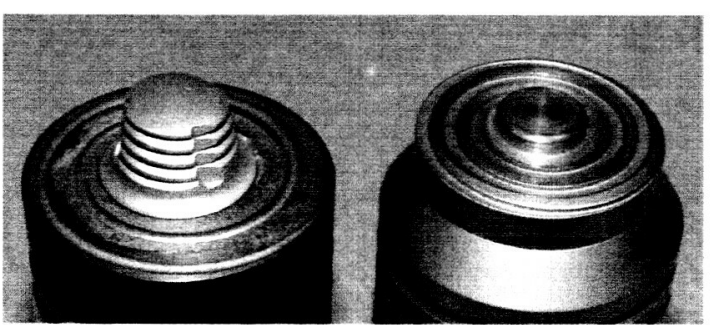

Figure 14: Pin-tools used for welding $1.27 \mathrm{~cm}$ (0.5 inch) thick GRCop-84. Tack tool on the right, full penetration tool on the left.

build-up during plunge. This excessive heat build up significantly altered welding characteristics during the early part of the weld.

Finally, the full-penetration weld pass was made. The key parameters that must be controlled during Friction Stir Welding are: 1) Rotation Speed (rpm) - Rotating speed of the pin-tool 2) Travel Speed (ipm) - Speed pin-tool traverses along the weld joint and 3) Pin-tool Plunge Depth (in) or Plunge Force (lbs) - Depth the shoulder "plunges" below the surface of the work piece. Alternatively the plunge force, or force the pin-tool exerts against the work piece.

Early in the development of parameters for welding the cylinders it became apparent that the welding process put heat energy into the part and fixture faster than the water-cooling system could reject it. This was significant because it meant that when welding parameters ( $\mathrm{rpm}$, ipm, and load) were fixed, the process would never reach a steady-state 
condition because the power input by the process was always higher than power taken out by the cooling system. To address this issue, the welding parameters were tapered from "hotter" to "colder" along the length of the weld. In other words the linear (along the length of the weld) heat input was reduced by the process to compensate for the linear increase in work piece temperature. This "tapered parameter" technique proved to be very successful at producing consistent weld results.

To date three cylinders have been welded - two $22 \mathrm{~cm}(8.66$ inch) ID, and one $13.8 \mathrm{~cm}(5.45$ inch) ID (Fig. 15). All welds completed have been free of radiographic indications. The first welds made had undercut that was deemed acceptable. Subsequent welds were made with tapered welding parameters and this undercut was eliminated.

Following welding and inspection the cylinders were annealed at $600^{\circ} \mathrm{C}$ for 30 minutes and the trim region of the cylinders was determined by referencing radiographs. The ends

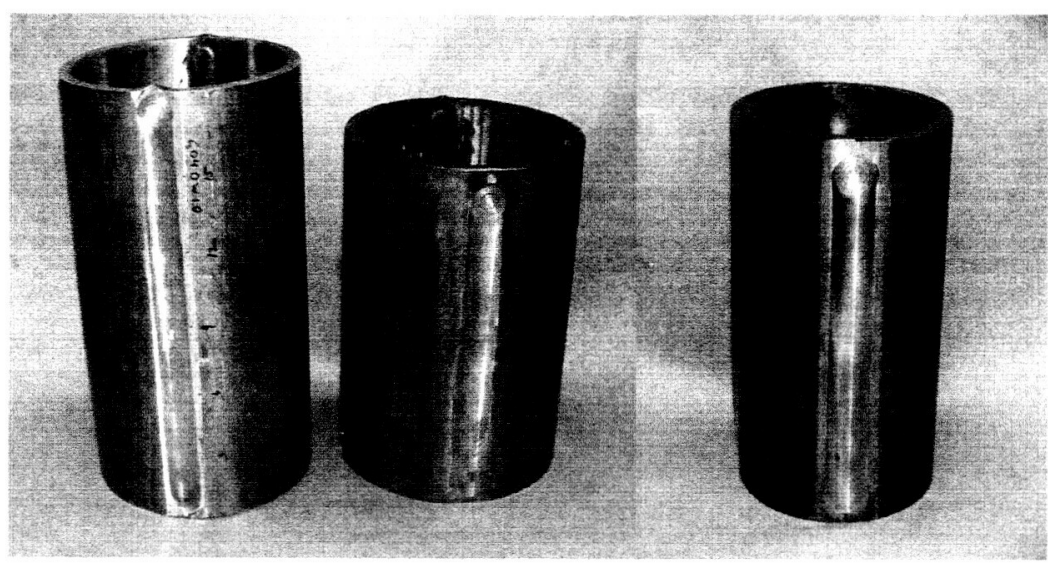

Figure 15: Cylinders completed after welding. of the cylinder must be trimmed due to the fact that the friction stir weld does not consume the entire length of the joint. Approximately $2.54 \mathrm{~cm}$ to 3.81 $\mathrm{cm}$ (1 to 1.5 inches) must be trimmed from both ends.

The cylinders were then shipped to Spintech for spin forming into the characteristic hour-glass shape of a combustion chamber liner. The cylinder was to be spun formed to a hour glass configuration leading to the final configuration of combustion chamber liners following the sequence of operations shown in Fig. 16. The cylinder performs were first mounted to a mandrel to form the smaller diameter end and move material thickness. Following this operation, the cylinder is mounted to a mandrel of the final configuration to achieve the hour glass shape.

After the initial spin forming operation, the friction stir welded material showed no visual evidence of separation or cracking. The forming temperature was held at $1400 \mathrm{~F}$ using a technique shown in Fig. 17. The GRCop- 84 material spun formed very similar to Narloy-Z. It was determined that GRCop-84 with friction stir welds are capable of being spun formed to a combustion chamber configuration as shown in Fig. 18. Following the spin forming operation, the liner will be thoroughly inspected and sectioned for metallurgical evaluation and mechanical property testing. A second liner will be final machined and hot fire tested by Boeing Rocketdyne.
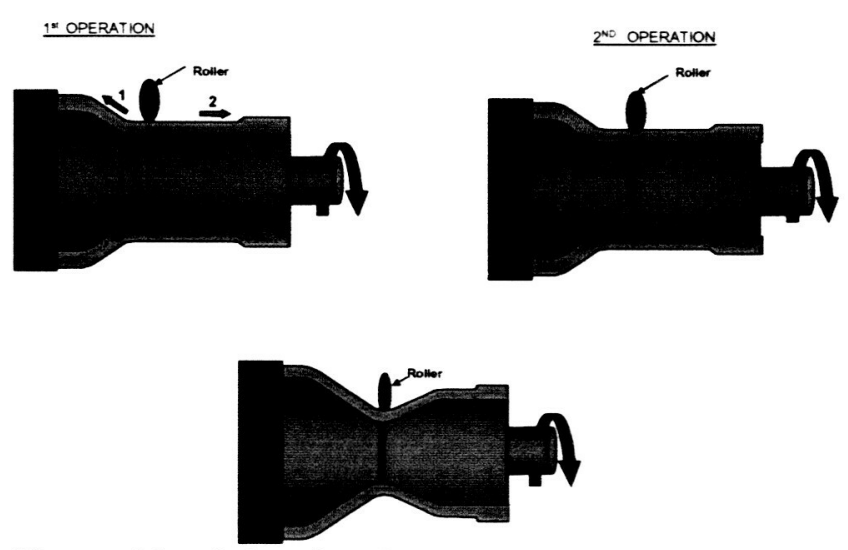

Figure 16: Spin forming sequence of operations to create hour glass shape.

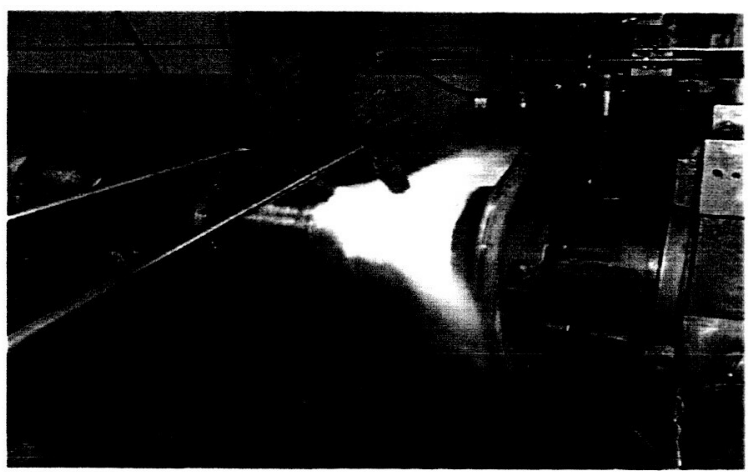

Figure 17: Preheating cylinder preform for forming operation. 


\section{Conclusions}

GRCop-84 exhibits properties well suited for use in a regeneratively cooled rocket engine liner. Production of the alloy has been successfully scaled up to produce powder in sufficient quantities for full scale hardware. The alloy was successfully extruded, rolled, formed, and welded into a subscale combustion chamber liner suitable for hot fire testing.

The friction stir weld process is well suited for GRCop-84. The solid state joining method produces welds with mechanical properties $96 \%$ of parent metal properties.

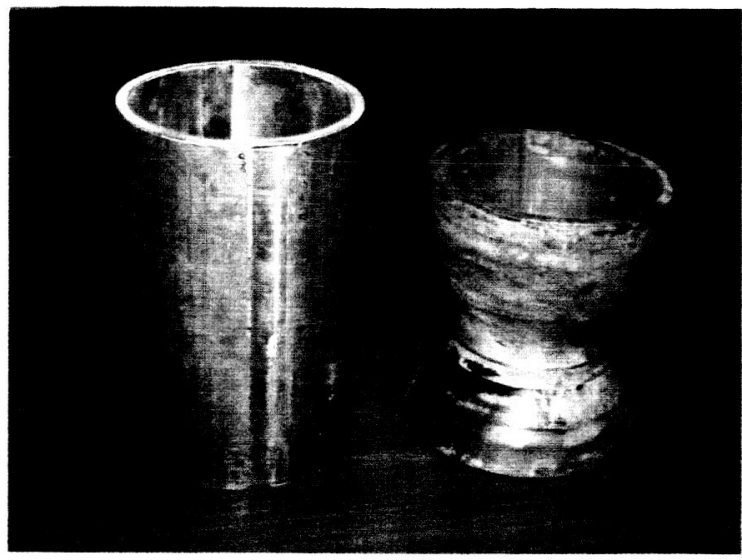

\section{Acknowledgments}

Figure 18: Spun formed liner prior to finish machining.

The authors would like to acknowledge the Next Generation Launch Technology program for funding this work. This manufacturing demonstration could not have been accomplished without the contributions of Crucible Research for producing the powder, H.C. Stark for extruding and rolling the plate, and Boeing Rocketdyne for testing the spun form liners.

\section{References}

'D.L. Ellis and R.L. Dreshfield, "Preliminary Evaluation of a Powder Metal Copper- $8 \mathrm{Cr}-4$ Nb Alloy," Proc. of the Advanced Earth-to-Orbit Conference, NASA CP-3174, Vol. 1, NASA MSFC, Huntsville, AL, (May 1992) pp. 18-27

${ }^{2}$ D.L. Ellis, R.L. Dreshfield, M.J. Verrilli, and D.G. Ulmer, "Mechanical Properties of a $\mathrm{Cu}-8 \mathrm{Cr}-4 \mathrm{Nb}$ Alloy," Proc. Of the Advanced Earth-to-Orbit Conference, NASA CP-3282, Vol. 1, Huntsville, AL (May 1994) pp. 32-41

${ }^{3}$ E. Shapiro and J. Crane, "Optimizing Conductivity, Formability And Relaxation Resistance In Copper Alloys," High Conductivity Copper and Aluminum Alloys, Eds. E. Ling and P.W. Taubenblat, The Metallurgical Society of AIME (TMS/AIME), Warrendale, PA (1984), pp.53-62

${ }^{4}$ M.F. Ashby, Oxide Dispersion Strengthening, AIME Conference Proc., New York, NY, (1966) p. 143

${ }^{5}$ R.D. McIntyre, Mater. Eng., Vol. 94, (1981), p. 42

${ }^{6}$ D.L. Ellis, recipitation Strengthened High Strength, High Conductivity Cu-Cr-Nb Alloys Produced By Chill Block Melt Spinning," Doctoral Dissertation, Case Western Reserve University, Cleveland, Oh (1989). Also available as NASA CR185114, NASA Lewis Research Center, Cleveland, OH (Sept. 1989)

'E. H. Schmidt. "Mechanical Property Data for Oxygen-Free High - Conductivity Copper and Boron Deoxidized Copper" NASA Tech. Brief 66-10273, (North American Aviation, Inc.), Feb., 1966

${ }^{8}$ T. Nagai, Z. Henmi, and S. Koda, "Annealing Behavior of Copper-Chromium, Copper-Zirconium and Copper-ZirconiumChromium Alloys," J. Japan Copper and Brass Res. Assn., Vol. 14, No.1, (1975), pp. 60-73 (CDA Extract 13298)

${ }^{9}$ J.J. Stephens, R.J. Bourcier, F.J. Vigil and D.T. Schmale, "Mechanical Properties of Dispersion Strengthened Copper: A Comparison of Braze Cycle Annealed and Coarse Grained Microstructures,", Sandia Report SAND 88-1351, Sandia National Labs, Albuquerque, NM (Sept.1988)

${ }^{10}$ Thrust Chamber Life Prediction, Vol. 1 - Mechanical and Physical Properties of High Performance Rocket Nozzle Materials, NASA CR-134806, NASA Lewis Research Center, Cleveland, OH (March 1975)

"NARloy-Z Properties

${ }^{12}$ D.D. Hom and H.F. Lewis, "Property Investigation of Copper-Base Alloys at Ambient and Elevated Temperatures," AEDC-TR-65-72, Arnold Engineering Development Center, Arnold Air Force Station, TN (July 1965)

${ }_{13}^{13}$ Copper creep

${ }^{14}$ GLIDCOP Creep

${ }^{15}$ AMZIRC Creep

${ }^{16}$ D.L. Ellis and G.M. Michal, "Mechanical and Thermal Properties of Two Cu-Cr-Nb Alloys and NARloy-Z," NASA CR198529, NASA Lewis Research Center, Cleveland, OH (Oct. 1996). 